\title{
Effect of blood pressure on the retinal vasculature in a multi-ethnic Asian population
}

\author{
V Swetha E Jeganathan ${ }^{1,2}$, Charumathi Sabanayagam ${ }^{2,3}$, E Shyong Tai ${ }^{4}$, Jeannette Lee ${ }^{3}$, Cong Sun ${ }^{1}$, \\ Ryo Kawasaki ${ }^{1}$, Sangeetha Nagarajan ${ }^{2}$, Maisie Ho Huey-Shi ${ }^{2}$, Mya Sandar ${ }^{2}$ and Tien Yin Wong ${ }^{1,2}$
}

Blood pressure has a significant effect on retinal arterioles. There are few data on whether this effect varies by race/ethnicity. We examined the relationship of blood pressure and retinal vascular caliber in a multi-ethnic Asian population. The study is population-based and cross sectional in design. A total of 3749 Chinese, Malay and Indian participants aged $\geqslant 24$ years residing in Singapore were included in the study. Retinal vascular caliber was measured using a computer program from digital retinal photographs. The associations of retinal vascular caliber with blood pressure and hypertension in each racial/ethnic group were analyzed. The main outcome measures are retinal arteriolar caliber and venular caliber. The results show that retinal arterioles were narrower in persons with uncontrolled/untreated hypertension $(140.0 \mu \mathrm{m})$ as compared with persons with controlled hypertension $(142.1 \mu \mathrm{m}, P=0.0001)$ and those with no hypertension $(146.0 \mu \mathrm{m}, P<0.0001)$. On controlling for age, gender, body mass index, lipids and smoking, each $10 \mathrm{~mm} \mathrm{Hg}$ increase in mean arterial blood pressure was associated with a $3.1 \mu \mathrm{m}$ decrease in arteriolar caliber $(P<0.0001)$, with a similar magnitude seen in all three racial/ethnic groups: $3.1 \mu \mathrm{m}$ in Chinese, $2.8 \mu \mathrm{m}$ in Malays and $3.2 \mu \mathrm{m}$ in Indians $(P<0.0001$ for all). Each $10 \mathrm{~mm} \mathrm{Hg}$ increase in mean arterial blood pressure was associated with a $1.8 \mu \mathrm{m}$ increase in venular caliber $(P<0.0001)$; furthermore, the magnitude of this effect was similar across the three racial/ethnic groups. The effect of blood pressure on the retinal vasculature was similar across three major racial/ethnic groups in Asia.

Hypertension Research (2009) 32, 975-982; doi:10.1038/hr.2009.130; published online 28 August 2009

Keywords: arteriolar narrowing; blood pressure; epidemiology; retinal arteriolar caliber; retinal venular caliber

\section{INTRODUCTION}

Hypertension affects multiple organs in the body, including the retinal vasculature. Retinal arteriolar narrowing is a marker of the early structural microvascular damage associated with chronic hypertension. ${ }^{1-3}$ Recent population-based studies using computer-based methods to measure retinal vascular caliber from fundus photographs have now established the strong linear relationship between elevated blood pressure (BP) and the severity of retinal arteriolar narrowing. ${ }^{4-6}$ Newer analyses suggest that elevated BP may also have a weaker effect on retinal venules. ${ }^{7-9}$ Prospective studies have further shown that retinal arteriolar narrowing predicts the incidence of hypertension ${ }^{10-12}$ and clinical cardiovascular events, such as stroke and coronary heart disease, independent of traditional risk factors. ${ }^{13-15}$ As such, an assessment of retinal vascular caliber may provide insights into early microvascular effects before the onset of clinical hypertension, and may help in the development of new treatment strategies targeted at microcirculation. ${ }^{16}$

However, whether the effects of $\mathrm{BP}$ on the retinal microvasculature are similar across different racial/ethnic groups remains unclear. There are well-recognized racial/ethnic differences in the association between BP and other markers of end-organ damage, including subclinical and clinical coronary artery disease, ${ }^{17}$ left ventricular hypertrophy, ${ }^{18}$ kidney disease $^{19}$ and cerebrovascular disease. ${ }^{20}$ Previous studies on the relationship of BP on the retinal vasculature have been conducted in predominantly Caucasian populations, ${ }^{7,9,21,22}$ with few studies in Asians, ${ }^{23,24}$ and even fewer directly comparing racial/ethnic differences. ${ }^{22}$

The purpose of this study is to examine the relationship between BP and retinal vascular caliber in a multi-ethnic Asian population of Chinese, Malays and Indians in Singapore. These three racial/ethnic groups in Asia represent more than two-third of the world's population.

${ }^{1}$ Centre for Eye Research Australia, University of Melbourne, Royal Victorian Eye and Ear Hospital, Melbourne, Victoria, Australia; ${ }^{2}$ Singapore Eye Research Institute, Yong Loo Lin School of Medicine, National University of Singapore, Singapore; ${ }^{3}$ Department of Community, Occupational and Family Medicine, Yong Loo Lin School of Medicine, National University of Singapore, Singapore and ${ }^{4}$ Department of Endocrinology, Singapore General Hospital, Singapore

Correspondence: Dr TY Wong, Singapore Eye Research Institute, Yong Loo Lin School of Medicine, Royal Victorian Eye and Ear Hospital, National University of Singapore, 11 Third Hospital Avenue, 168751, Singapore.

E-mail: twong@unimelb.edu.au

Meeting Presentation: Royal Australian and New Zealand College of Ophthalmologists Congress, Melbourne, Australia, November 2008.

Received 31 March 2009; revised 20 July 2009; accepted 20 July 2009; published online 28 August 2009 


\section{METHODS}

\section{Study population}

This study used data from the Singapore Prospective Study Program and Singapore Cardiovascular Cohort Study 2, which included participants from one of four previous cross-sectional studies: Thyroid and Heart Study 1982$1984,{ }^{25}$ National Health Survey $1992,{ }^{26}$ National University of Singapore Heart Study $1993-1995^{27}$ or National Health Survey $1998{ }^{28}$ All studies involved a random sample of individuals from the Singapore population, aged 24-95 years, with disproportionate sampling stratified by ethnicity to increase the number of minority ethnic groups (Malays and Indians). The Ministry of Health, Singapore, selected the study population.

Figure 1 shows a flow diagram of subjects that were considered for inclusion in the study. From 2003 to 2007, all 10747 participants were invited to participate in this study by linking their unique national identification numbers with national registries; 85 individuals had errors in their identification (national registration identity card) number (preventing linkage to national registries), 555 had died before contact was made, 37 died before attending the clinic, and 6 had left the country. Participants were contacted first through mail, then by phone and if there was no response or no available phone number, interviewers visited the home; three different home visits were made before participants were deemed non-contactable (2292 individuals). Another 30 contacted participants refused to participate, leaving 7742 who were interviewed at their homes. The interviewer-administered questionnaire included data on demographic and lifestyle (alcohol intake, smoking) factors as well as medical history.

All 7742 participants were then invited for a clinical examination that included systemic and ocular examination, retinal photography and laboratory investigations, of which 5157 attended. Logistic constraints, due to availability of one retinal camera, resulted in only 1 in 2 Chinese participants (the group with the largest sample size) who were asked to undergo retinal photography between 19 March 2005 and 20 February 2006. Consequently, 1020 (of 5517) Chinese participants did not undergo retinal photography. Out of the remaining 4137 participants, retinal photographs were obtained for virtually all those who underwent the procedure (4098 or $99.1 \%$ of 4137 ). Participants with

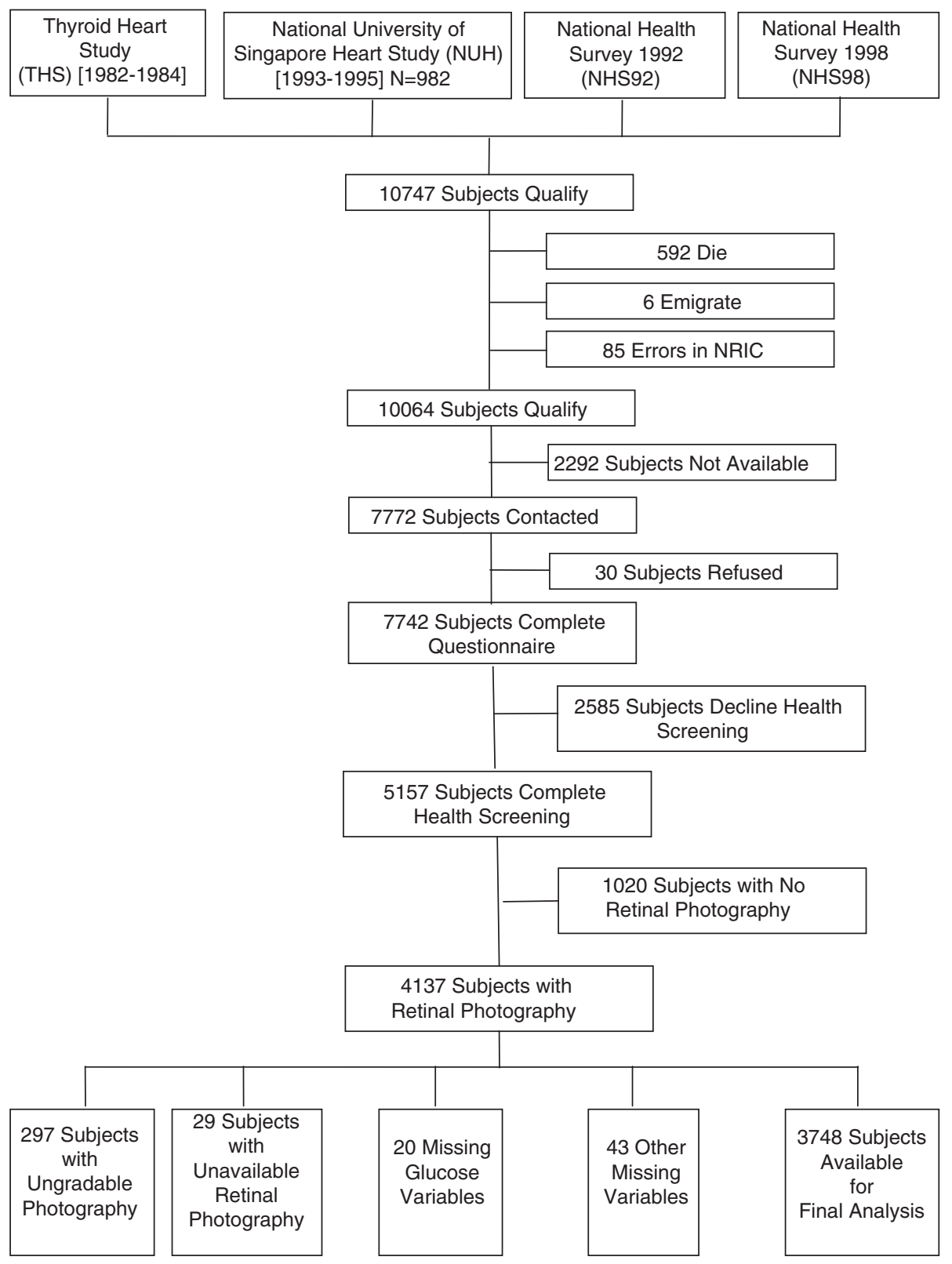

Figure 1 Flow diagram of subjects that were considered for inclusion in the study. 
ungradable retinal photographs ( $n=297$ ), missing information on BP or other relevant variables $(n=52)$ were then excluded, leaving 3749 for the final analysis ( $48.4 \%$ of 7742 eligible participants). Excluded participants were found to be older and had higher high-density lipoprotein cholesterol, systolic BP and lower low-density lipoprotein cholesterol (all significant at $P<0.05$ ) than included participants. The Code of Ethics of the World Medical Association (the Declaration of Helsinki Principles, 1964 and Declaration of Tokyo, 1975, as revised in 1983) was followed, and institutional review board approval was granted at each study site. All participants provided written informed consent.

\section{Assessment of hypertension}

Systolic and diastolic BP (SBP and DBP) were evaluated using a digital automatic BP monitor (Dinamap model Pro100V2; Criticon, Norderstedt, Germany). BP assessments were carried out by two operators who were trained in the standardized technique. ${ }^{29}$ The BP was measured twice, at an interval of $5 \mathrm{~min}$, with participants seated for five minutes with legs uncrossed. A proper sized cuff was used on the participant's right arm at the heart level, unless contraindicated. The second reading was taken after a lapse of 1-2 min. A third measurement was taken if the BP differed by more than $10 \mathrm{~mm} \mathrm{Hg}$ in systolic and $5 \mathrm{~mm} \mathrm{Hg}$ in diastolic readings. The mean between the two closest readings were then taken as the BP of that participant. In the case in which Dinamap was unable to detect a reading, a manual reading of BP was taken. The use of antihypertensive medication was obtained from the questionnaire. Names and doses of the participant's regular antihypertensive medications were recorded. Medications were categorized as $\beta$-blocker, angiotensin-converting enzyme inhibitor, calcium channel blocker, angiotensin receptor antagonist, diuretic, $\alpha$-adrenergic blocker, vasodilator or centrally acting drug. Mean arterial BP (MABP) was calculated as $2 / 3$ of the DBP plus $1 / 3$ of the SBP value.

Hypertension was defined as a condition with $\mathrm{SBP} \geqslant 140 \mathrm{~mm} \mathrm{Hg}$, $\mathrm{DBP} \geqslant 90 \mathrm{~mm} \mathrm{Hg}$, or a physician diagnosis of hypertension. Hypertension was further classified into controlled hypertension in participants using antihypertensive medication, with SBP $<140 \mathrm{~mm} \mathrm{Hg}$ and DBP $<90 \mathrm{~mm} \mathrm{Hg}$; or uncontrolled hypertension in participants with $\mathrm{SBP} \geqslant 140 \mathrm{~mm} \mathrm{Hg}$ or $\mathrm{DBP} \geqslant 90 \mathrm{~mm} \mathrm{Hg}$, regardless of antihypertensive medication use.

Retinal photography and measurement of retinal vascular caliber Digital fundus photographs were taken using a $45^{\circ}$ digital retinal camera (Canon CR-DGi with a 10D SLR back, Canon, Tokyo, Japan) after pupil dilatation with $1 \%$ tropicamide and $2.5 \%$ phenylephrine. Two retinal images of each eye were obtained, one centered at the optic disc and another centered at the fovea, identical to the Early Treatment for Diabetic Retinopathy Study standard fields 1 and $2 .{ }^{30}$

Retinal vascular caliber was measured at the Retinal Vascular Imaging Centre, University of Melbourne using a computer-assisted software (IVAN, University of Wisconsin, Madison, WI, USA) according to the standardized protocol used in other population-based studies. ${ }^{22,23,31}$ A trained grader, masked to participant characteristics, carried out the vessel measurements on the optic disc-centered image of the right eye for most participants, and of the left eye in those without gradable right eye images. All arterioles and venules crossing through a specified zone $0.5-1$ disc diameter away from the optic disc margin were measured and summarized as the central retinal artery equivalent (CRAE) or central retinal vein equivalent (CRVE), respectively using a modification of the Parr-Hubbard formula ${ }^{32}$ as described by Knudtson et al..$^{33}$ The retinal arterio-venous ratio (AVR) was calculated as the ratio of CRAE to CRVE. ${ }^{32}$ A retinal photograph having less than six acceptable measurements of either vessel type was considered ungradable. Two hundred randomly selected retinal photographs were re-graded by the same assessor to assess reproducibility, with intra-grader reliability intraclass correlation coefficients of 0.99 (95\% confidence interval (95\% CI): 0.98-0.99) for CRAE and 0.94 (95\% CI: 0.92-0.96) for CRVE.

\section{Assessment of covariates}

Age was defined as the age at the time of health screening, when BP and retinal images were captured. Height was quantified in centimeters, using a wallmounted measuring tape; weight was assessed in kilograms, using a digital scale and body mass index (BMI) was calculated as 'body weight divided by the square of body height $\left(\mathrm{kg} \mathrm{m}^{-2}\right)$.' Venous blood samples were analyzed on the same day at the National University Hospital Reference Laboratory for biochemical testing of serum total cholesterol, high-density lipoprotein and low-density lipoprotein cholesterol, triglycerides and fasting glucose. Diabetes mellitus was identified from fasting plasma glucose level of $\geqslant 7 \mathrm{mmoll}^{-1}$, selfreported use of diabetic medication or physician-diagnosed diabetes. Current smokers were defined as those who were currently smoking every day or every few days.

\section{Statistical analysis}

Statistical analyses were carried out using SAS version 9.1. software (SAS Institute, Cary, NC, USA). Characteristics of the participants were compared within ethnic groups by analysis of variance or $\chi^{2}$ tests, whichever being appropriate. Retinal arteriolar (CRAE) and venular (CRVE) caliber and AVR

Table 1 Characteristics of study participants based on race/ethnicity

\begin{tabular}{|c|c|c|c|c|c|}
\hline Characteristics & Whole population $(\mathrm{n}=3749)$ & Chinese $(n=2215)$ & Malay $(\mathrm{n}=807)$ & Indian $(\mathrm{n}=727)$ & P-value \\
\hline Gender, male (\%) & 48.2 & 47.6 & 49.3 & 48.7 & 0.7 \\
\hline Hypertension (\%) & 39.3 & 36.6 & 45.9 & 40.6 & $<0.0001$ \\
\hline Diabetes (\%) & 11.4 & 7.1 & 14.0 & 21.7 & $<0.0001$ \\
\hline Current smoking (\%) & 12.0 & 10.3 & 17.0 & 11.7 & $<0.0001$ \\
\hline Alcohol consumption (\%) & 33.7 & 44.6 & 6.4 & 30.8 & $<0.0001$ \\
\hline Age, mean \pm s.d. (years) & $49.2(11.3)$ & $48.7(11.7)$ & $48.9(11.0)$ & $50.7(10.3)$ & 0.0002 \\
\hline Systolic blood pressure, mean \pm s.d. $(\mathrm{mm} \mathrm{Hg})$ & $131.6(20.2)$ & $129.5(19.8)$ & $136.3(20.2)$ & $132.6(20.4)$ & $<0.0001$ \\
\hline Diastolic blood pressure, mean \pm s.d. $(\mathrm{mm} \mathrm{Hg})$ & $77.8(10.7)$ & $77.0(10.7)$ & $79.5(10.6)$ & $78.6(10.6)$ & $<0.0001$ \\
\hline Serum glucose, mean \pm s.d. $\left(\mathrm{mmoll}^{-1}\right)$ & $5.2(1.6)$ & $5.0(1.2)$ & $5.3(1.8)$ & $5.7(2.2)$ & $<0.0001$ \\
\hline Body mass index, mean \pm s.d. $\left(\mathrm{kg} \mathrm{m}^{-2}\right)$ & $24.3(5.2)$ & $22.9(3.6)$ & $26.3(4.8)$ & $26.2(7.6)$ & $<0.0001$ \\
\hline Total cholesterol, mean \pm s.d. $\left(\mathrm{mmol} \mathrm{I}^{-1}\right)$ & $5.2(1.0)$ & $5.2(0.9)$ & $5.5(1.0)$ & $5.2(0.9)$ & $<0.0001$ \\
\hline HDL cholesterol, mean \pm s.d. $\left(\mathrm{mmol}^{-1}\right)$ & $1.4(0.4)$ & $1.5(0.4)$ & $1.4(0.3)$ & $1.2(0.3)$ & $<0.0001$ \\
\hline LDL cholesterol, mean \pm s.d. $\left(\mathrm{mmol} \mathrm{I}^{-1}\right)$ & $3.2(0.9)$ & $3.1(0.9)$ & $3.4(1.0)$ & $3.3(0.8)$ & $<0.0001$ \\
\hline Triglycerides, mean \pm s.d., mmoll-1 & $1.4(0.9)$ & $1.3(0.9)$ & $1.5(1.2)$ & $1.4(0.7)$ & $<0.0001$ \\
\hline CRAE, mean \pm s.d. $(\mu \mathrm{m})$ & $143.8(14.3)$ & $143.4(14.3)$ & $145.4(13.8)$ & $143.0(14.5)$ & 0.0008 \\
\hline CRVE, mean \pm s.d. $(\mu \mathrm{m})$ & $220.8(20.7)$ & $219.5(20.3)$ & $226.9(20.7)$ & $218.0(20.6)$ & $<0.0001$ \\
\hline AVR, mean \pm s.d. & $0.65(0.1)$ & $0.66(0.1)$ & $0.64(0.1)$ & $0.66(0.1)$ & $<0.0001$ \\
\hline
\end{tabular}

Abbreviations: AVR, arterio-venous ratio; CRAE, central retinal artery equivalent; CRVE, central retinal vein equivalent; HDL, high-density lipoprotein; LDL, low-density lipoprotein.

aThe $P$-value represents difference in characteristics by ethnicity based on the analysis of variance or $\chi^{2}$ test as appropriate. 
were analyzed as continuous variables. We used analysis of covariance to estimate mean retinal vascular calibers in association with normal BP, controlled hypertension and uncontrolled hypertension. We carried out these analyses initially for the total population and then separately for the three ethnic groups (Malays, Chinese and Indians) in three multivariable models: model 1: adjustment for age, gender and ethnicity; model 2: adjustment for variables in model 1 plus diabetes status, BMI, total cholesterol, triglycerides and current smoking (ethnicity was not included for ethnicity-specific models); model 3: adjustment for variables in model 2 plus CRVE in models for CRAE (and vice versa), which accounts for potential confounding from fellow vascular caliber. ${ }^{34}$ Test of trend was determined by treating categorical risk factors (for example, categories of BP) as continuous ordinal variables in the multiple linear regression models. Using multiple linear regression models, we also estimated the mean difference in CRAE, CRVE and AVR with MABP as continuous variables in the same three models. To further account for the effect of antihypertensive medication, we repeated the analysis in model 3, with additional adjustment for antihypertensive medication use. Statistical interaction by age, gender, ethnicity and antihypertensive medication intake in the association between CRAE and MABP was tested by including cross-product interaction terms. In a supplementary analysis, we examined the association between CRAE and MABP stratified by age groups (younger ( $<40$ years) and older $(\geqslant 40$ years $))$.

\section{RESULTS}

The study population consisted of 2215 Chinese (59.1\%), 807 Malays $(21.5 \%)$ and 727 Indian (19.4\%) participants. The prevalence of hypertension in the total population was $39.3 \%$ and this was highest among the Malays $(45.9 \%)$. Among those with known history of hypertension $(n=759), 83.5 \%$ were on antihypertensive medication. Out of these, $30 \%$ of the participants on antihypertensive medication had their BP controlled.

Selected characteristics of the study population stratified by ethnicity are shown in Table 1. Malays were more likely to be smokers, had higher SBP and DBP, BMI, total cholesterol, low-density lipoprotein cholesterol, triglycerides, mean CRAE and mean CRVE compared with Chinese and Indians. Chinese were more likely to be alcohol drinkers and Indians were more likely to be older, had higher serum glucose and low highdensity lipoprotein cholesterol level than did Malays and Chinese.

Table 2 shows the relationship of selected risk factors with retinal vascular caliber. After adjusting for age and gender, CRAE was associated with age, gender, smoking, alcohol consumption and BMI, whereas CRVE was associated with age, FPG, smoking, alcohol consumption, BMI and lipid profile.
Table 3 shows estimated mean CRAE, CRVE and AVR by hypertension status across ethnicity. CRAE was narrowest in participants with uncontrolled/untreated hypertension as compared with controlled hypertension and no hypertension. In model 3 after controlling for relevant risk factors and CRVE, CRAE was found to be $140.0 \mu \mathrm{m}$ in persons with uncontrolled/untreated hypertension, $142.1 \mu \mathrm{m}$ in persons with controlled hypertension and $146.0 \mu \mathrm{m}$ those with no hypertension $(P$-value for trend $<0.0001)$. After adjusting for potential confounders in model 3, CRVE was significantly wider in participants with uncontrolled/untreated hypertension compared with participants with normal BP $(222.8 v s .219 .5 \mu \mathrm{m}$, respectively; $P<0.0001)$ in the total population.

Figure 2 shows the trend of narrowing of retinal arteriolar caliber with increasing MABP in all three ethnic groups, adjusting for covariates in model 3 ( $P$-value for trend $<0.0001$ ).

Table 3 shows the mean change of CRAE, CRVE and AVR for each $10 \mathrm{~mm} \mathrm{Hg}$ increase in MABP, controlling for covariates in three different models. In model 3, each $10 \mathrm{~mm} \mathrm{Hg}$ increase in MABP was associated with a $3.1-\mu \mathrm{m}(P<0.0001)$ decrease in CRAE and a $1.8-\mu \mathrm{m}$ $(P<0.0001)$ increase in CRVE in the total population. The magnitude of the change in CRAE/CRVE was similar in all three racial/ethnic groups. For example, each $10 \mathrm{~mm} \mathrm{Hg}$ increase in MABP was associated with a 3.1- $\mu \mathrm{m}$ decrease in CRAE in Chinese, $2.8 \mu \mathrm{m}$ in Malays and $3.2 \mu \mathrm{m}$ in Indians $(P<0.0001$ for all). Table 4 shows the effect of changes in MABP on retinal vascular calibers, with regard to race/ ethnicity. Results were largely similar in different racial/ethnic groups. The results were also similar in analysis repeated using SBP and DBP instead of MABP (data not shown).

The inverse association of MABP and CRAE remained even after further adjustment for antihypertensive medication $(-1.9 \mu \mathrm{m} ; 95 \%$ CI: $-2.7,-1.2, P<0.0001$, data not shown). Moreover, this association was observed in all three ethnic groups consistently. There was no role for race/ethnicity, gender and antihypertensive medication in the association between CRAE and MABP. However, there was a significant interaction between age and MABP on CRAE ( $P$-value for interaction $=0.0004)$. When stratified by age group of $<40$ and $\geqslant 40$ years, each $10 \mathrm{~mm} \mathrm{Hg}$ increase in MABP was associated with $-3.3 \mu \mathrm{m}$ change in the mean CRAE (95\% CI: $-3.7,-3.0 ; P<0.0001)$ in the younger age group (age $<40$ years) compared with $-1.9 \mu \mathrm{m}$ change of mean CRAE (95\% CI: $-2.7,-1.0 ; P<0.0001)$ in the older age group (age $\geqslant 40$ years) in model 3 .

Table 2 Relationship of selected risk factors with retinal vascular caliber

\begin{tabular}{|c|c|c|c|c|c|}
\hline \multirow[b]{2}{*}{ Risk factors } & \multirow[b]{2}{*}{ Unit change } & \multicolumn{2}{|c|}{ Retinal arteriolar caliber (CRAE) } & \multicolumn{2}{|c|}{ Retinal venular caliber $(C R V E)^{a}$} \\
\hline & & $\beta(S E)$ & $P$-value & $\beta(S E)$ & $P$-value \\
\hline Age & Per 10 years increase & $-2.63(0.20)$ & $<0.0001$ & $-4.0(0.29)$ & $<0.0001$ \\
\hline Gender & Men vs. women & $4.95(0.45)$ & $<0.0001$ & $0.28(0.66)$ & 0.67 \\
\hline FPG & Per s.d. increase ( $\left.1.6 \mathrm{mmol}^{-1}\right)$ & $0.12(0.23)$ & 0.61 & $1.37(0.33)$ & $<0.0001$ \\
\hline Cigarette smoking & Current vs. never/past & $3.74(0.72)$ & $<0.0001$ & $9.25(1.06)$ & $<0.0001$ \\
\hline Alcohol drinking & Current vs. never/past & $-1.63(0.56)$ & 0.004 & $-3.50(0.82)$ & $<0.0001$ \\
\hline BMI & Per s.d. increase $\left(5.2 \mathrm{~kg} \mathrm{~m}^{-2}\right.$ ) & $-0.89(0.23)$ & 0.0001 & $1.17(0.34)$ & 0.0007 \\
\hline Total cholesterol & Per s.d. increase $\left(0.95 \mathrm{mmol} \mathrm{I}^{-1}\right)$ & $-0.35(0.23)$ & 0.12 & $0.85(0.33)$ & 0.01 \\
\hline HDL cholesterol & Per s.d. increase $\left(0.36 \mathrm{mmol}^{-1}\right)$ & $-0.27(0.24)$ & 0.27 & $-2.25(0.36)$ & $<0.0001$ \\
\hline LDL cholesterol & Per s.d. increase $\left(0.88 \mathrm{mmol} \mathrm{I}^{-1}\right)$ & $-0.16(0.23)$ & 0.49 & $1.18(0.33)$ & 0.0004 \\
\hline Triglycerides & Per s.d. increase $\left(0.93 \mathrm{mmol} \mathrm{I}^{-1}\right)$ & $-0.27(0.23)$ & 0.24 & $1.10(0.34)$ & 0.001 \\
\hline
\end{tabular}

Abbreviations: $\beta$, regression coefficient; BMI, body mass index, HDL, high-density lipoprotein; LDL, low-density lipoprotein.

aModel adjusted for age, gender and ethnicity. 
Table 3 Relationship of retinal vascular caliber with hypertension status based on race/ethnicity

\begin{tabular}{|c|c|c|c|c|}
\hline & $\begin{array}{c}\text { No } \\
\text { Hypertension } \\
(\mathrm{n}=2274)\end{array}$ & $\begin{array}{l}\text { Hypertension, } \\
\text { controlled } \\
(\mathrm{n}=223)\end{array}$ & $\begin{array}{c}\text { Hypertension, } \\
\text { uncontrolled/ } \\
\text { untreated } \\
(\mathrm{n}=1252)\end{array}$ & $\mathrm{P}$-value ${ }^{\mathrm{a}}$ \\
\hline \multicolumn{5}{|c|}{ Retinal arteriolar caliber (CRAE) } \\
\hline \multicolumn{5}{|l|}{ Model $1^{a}$} \\
\hline All individuals & $146.2(0.3)$ & $142.5(0.9)^{b}$ & $139.5(0.4)^{b}$ & $<0.0001$ \\
\hline \multicolumn{5}{|l|}{ Model $2^{\mathrm{c}}$} \\
\hline All individuals & $146.2(0.3)$ & $142.4(0.9)^{b}$ & $139.6(0.4)^{b}$ & $<0.0001$ \\
\hline Chinese & $145.6(0.4)$ & $141.7(1.2)^{\mathrm{b}}$ & $139.3(0.6)^{b}$ & $<0.0001$ \\
\hline Malays & $148.3(0.7)$ & $145.6(2.0)$ & $141.6(0.8)^{b}$ & $<0.0001$ \\
\hline Indians & $146.0(0.7)$ & $141.9(2.1)$ & $138.1(0.9)^{b}$ & $<0.0001$ \\
\hline \multicolumn{5}{|l|}{ Model $3^{d}$} \\
\hline All individuals & $146.0(0.3)$ & $142.1(0.8)^{b}$ & $140.0(0.4)^{b}$ & $<0.0001$ \\
\hline Chinese & $145.3(0.3)$ & $141.5(1.0)^{b}$ & $139.9(0.5)^{b}$ & $<0.0001$ \\
\hline Malays & $147.8(0.6)$ & $143.7(1.7)$ & $142.5(0.7)^{\mathrm{b}}$ & $<0.0001$ \\
\hline Indians & $146.2(0.6)$ & $141.6(1.9)$ & $138.7(0.9)^{\mathrm{b}}$ & $<0.0001$ \\
\hline \multicolumn{5}{|c|}{ Retinal venular caliber (CRVE) } \\
\hline \multicolumn{5}{|l|}{ Model $1^{\mathrm{a}}$} \\
\hline All individuals & $221.2(0.4)$ & $222.0(1.4)$ & $220.1(0.6)$ & $<0.0001$ \\
\hline \multicolumn{5}{|l|}{ Model $2^{\mathrm{c}}$} \\
\hline All individuals & $221.4(0.4)$ & $221.9(1.4)$ & $219.6(0.6)$ & $<0.0001$ \\
\hline Chinese & $220.3(0.6)$ & $220.1(1.7)$ & $217.9(0.8)$ & $<0.0001$ \\
\hline Malays & $228.2(1.0)$ & $232.6(3.1)$ & $224.3(1.2)$ & $<0.0001$ \\
\hline Indians & $218.3(1.0)$ & $215.8(2.9)$ & $217.7(1.3)$ & $<0.0001$ \\
\hline \multicolumn{5}{|l|}{ Model $3^{d}$} \\
\hline All individuals & $219.5(0.4)$ & $222.9(1.2)$ & $222.8(0.5)^{b}$ & $<0.0001$ \\
\hline Chinese & $218.6(0.5)$ & $221.4(1.6)$ & $221.1(0.8)^{b}$ & $<0.0001$ \\
\hline Malays & $226.1(1.0)$ & $231.9(2.8)$ & $228.3(1.2)$ & $<0.0001$ \\
\hline Indians & $216.2(0.9)$ & $216.6(2.6)$ & $221.3(1.2)^{\mathrm{b}}$ & $<0.0001$ \\
\hline \multicolumn{5}{|c|}{ Arterio-venous ratio (AVR) } \\
\hline \multicolumn{5}{|l|}{ Model $1^{a}$} \\
\hline All individuals & $0.664(0.001)$ & $0.646(0.004)$ & $0.638(0.002)$ & $<0.0001$ \\
\hline \multicolumn{5}{|l|}{ Model $2^{c}$} \\
\hline All individuals & $0.663(0.001)$ & $0.646(0.004)$ & $0.639(0.002)$ & $<0.0001$ \\
\hline Chinese & $0.663(0.002)$ & $0.648(0.005)$ & $0.642(0.003)$ & $<0.0001$ \\
\hline Malays & $0.652(0.003)$ & 0.629 (0.009) & $0.634(0.003)$ & $<0.0001$ \\
\hline Indians & $0.671(0.003)$ & $0.660(0.009)$ & $0.637(0.004)$ & $<0.0001$ \\
\hline
\end{tabular}

Data presented are analysis of covariance models showing mean \pm s.e. of retinal arteriolar and

venular caliber (in $\mu \mathrm{m}$ ).

b $P$-value based on analysis of covariance models, comparing hypertension controlled and hypertension uncontrolled with no hypertension.

cModel 2: adjusted for age, gender, ethnicity (except for ethnicity-specific models), diabetes status, body mass index, total cholesterol, triglycerides, current drinking and current smoking. dModel 3: adjusted for variables in Model 2 and also for CRVE (in models of CRAE), and CRAE (in models of CRVE).

In comparison with non-hypertensive participants, mean CRAE for participants with controlled hypertension achieved by antihypertensive medication was smaller $(146.0 \pm 0.3 v s .142 .2 \pm 0.8 \mu \mathrm{m}$, respectively; $P=0.0001)$. In comparison, the mean CRVE of nonhypertensive individuals and those with hypertension controlled by

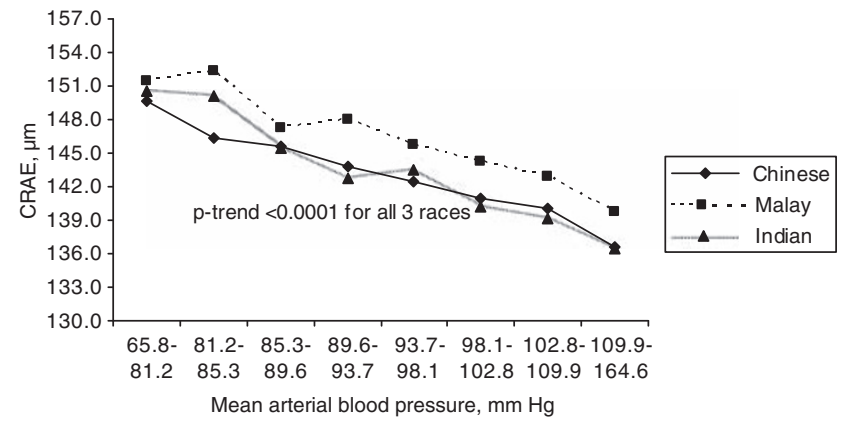

Figure 2 Estimated Retinal Arteriolar Caliber (CRAE), by mean arterial blood pressure and by race/ethnicity, adjusted for variables in Model 3 (age, gender, diabetes status, body mass index, total cholesterol, triglycerides, current smoking and central retinal vein equivalent).

antihypertensive medication was not significantly different (219.5 \pm 0.4 vs. $222.7 \pm 1.3 \mu \mathrm{m}$, respectively; $P=0.08$ ). There was no statistically significant difference in mean CRAE or CRVE based on the type of antihypertensives medication.

Finally, Table 5 shows the relationship of retinal vascular caliber with blood pressure categories, as defined by the European Society of Hypertension and the European Society of Cardiology guidelines for the management of arterial hypertension. Following multivariable adjustment, CRAE narrowing was more marked in those with Grade 3 hypertension, compared with those with Grade 2 or Grade 1 hypertension $(\beta:-10.8 \pm 0.9,-8.6 \pm 0.7,-8.1 \pm 0.6$, for hypertension Grades 1, 2 and 3, respectively, $P<0.0001$ ). There was no clear pattern of CRVE widening and different Grades of hypertension ( $\beta: 4.8 \pm 0.9,3.9 \pm 1.1,4.8 \pm 1.4$, for hypertension Grades 1,2 and 3, respectively, $P \leqslant 0.0004)$.

\section{DISCUSSION}

In this study, we examined the relationship of BP and retinal vascular caliber in the three major racial/ethnic groups in Asia. Increasing levels of BP was strongly associated with the narrowing of retinal arterioles and slight widening of retinal venules, with the magnitude of associations similar across Chinese, Malays and Indians.

We show that Asians with hypertension have narrower retinal arteriolar caliber than those without hypertension, and that among persons with hypertension, those with uncontrolled/untreated hypertension have greater degree of narrowing than those with controlled hypertension. This observation has been reported in predominantly white populations in both persons with newly diagnosed ${ }^{6,22}$ and chronic ${ }^{35}$ hypertension. The relationship of BP and retinal arteriolar caliber was monotonic and linear, and consistent with other population-based studies. ${ }^{5,6,8,9}$ For example, in our study, comparison for older Malays (aged $\geqslant 40$ years) in the cohort showed that for each $10 \mathrm{~mm} \mathrm{Hg}$ increase in MABP, retinal arterioles narrowed by $1.9 \mu \mathrm{m}$, a magnitude which is less than that observed in the Singapore Malay Eye Study (narrowed by $2.7 \mu \mathrm{m}$ ), the Funagata Eye Study $(2.8 \mu \mathrm{m})$ and Beaver Dam Eye Study in white population $(2.3 \mu \mathrm{m}))^{7,23,24}$

We also found that persons with hypertension had wider retinal venules compared with participants with normal BP, independent of hypertension control and smoking status. Each $10 \mathrm{~mm} \mathrm{Hg}$ increase in MABP was associated with a $1.8-\mu \mathrm{m}$ increase in retinal venular caliber in the multivariable model. This finding has now been observed in two other studies, the Rotterdam and Blue Mountains Eye Study. ${ }^{36,37}$ In addition, the Blue Mountains Eye Study also reported that persons 
Table 4 Effect of changes in MABP on retinal vascular calibers based on race/ethnicity

\begin{tabular}{|c|c|c|c|c|c|c|}
\hline \multirow[b]{2}{*}{$M A B P, 10 \mathrm{~mm} \mathrm{Hg}$} & \multicolumn{2}{|c|}{ Retinal arteriolar caliber (CRAE) } & \multicolumn{2}{|c|}{ Retinal venular caliber (CRVE) } & \multicolumn{2}{|c|}{ Arteriole to venule ratio (AVR) } \\
\hline & Mean Change $(95 \% \mathrm{Cl}), \mu \mathrm{m}^{\mathrm{a}}$ & P-value & Mean change $(95 \% \mathrm{Cl}), \mu \mathrm{m}^{\mathrm{a}}$ & P-value & Mean change $(95 \% \mathrm{Cl})^{\mathrm{a}}$ & P-value \\
\hline All individuals & $-3.3(-3.7,-2.9)$ & $<0.0001$ & $-0.5(-1.1,-0.06)$ & 0.08 & $-0.014(-0.015,-0.011)$ & $<0.0001$ \\
\hline \multicolumn{7}{|l|}{ Model $2^{c}$} \\
\hline All individuals & $-3.4(-3.8,-3.0)$ & $<0.0001$ & $-0.9(-1.5,-0.3)$ & 0.002 & $-0.013(-0.014,-0.011)$ & $<0.0001$ \\
\hline Indians & $-3.4(-4.2,-2.6)$ & $<0.0001$ & $-0.5(-1.7,0.7)$ & 0.4 & $-0.014(-0.017,-0.010)$ & $<0.0001$ \\
\hline \multicolumn{7}{|l|}{ Model $3^{\mathrm{d}}$} \\
\hline All individuals & $-3.1(-3.4,-2.8)$ & $<0.0001$ & $1.8(1.3,2.3)$ & $<0.0001$ & - & \\
\hline Chinese & $-3.1(-3.6,-2.7)$ & $<0.0001$ & $1.7(0.9,2.4)$ & $<0.0001$ & - & \\
\hline Malays & $-2.8(-3.5,-2.1)$ & $<0.0001$ & $0.7(-0.5,1.8)$ & 0.25 & - & \\
\hline Indians & $-3.2(-3.9,-2.5)$ & $<0.0001$ & $2.0(0.9,3.1)$ & 0.0004 & - & \\
\hline
\end{tabular}

Abbreviations: $\mathrm{Cl}$, class interval; MABP, mean arterial blood pressure.

Regression coefficient of MABP in linear regression models for CRAE, CRVE and AVR.

Model 1: Adjustment for age, gender and ethnicity.

cModel 2: Adjustment for age, gender, ethnicity, diabetes status, body mass index, total cholesterol, triglycerides, current drinking and current smoking, except in ethnicity-specific strata

(no adjustment for ethnicity).

dModel 3: Adjustment for variables in Model 2 plus venular caliber (in models of arteriolar caliber) and arteriolar caliber (in models of venular caliber).

Table 5 Relationship of retinal vascular caliber with ESH/ESC blood pressure categories ${ }^{\mathrm{a}}$

\begin{tabular}{|c|c|c|c|c|c|c|}
\hline \multirow{2}{*}{ Unit change } & \multicolumn{2}{|c|}{ Model $1^{\mathrm{b}}$} & \multicolumn{2}{|c|}{ Model $x^{c}$} & \multicolumn{2}{|c|}{ Model $3^{\mathrm{d}}$} \\
\hline & $\beta$ (s.e.) & $\mathrm{P}$-value $\mathrm{e}^{\mathrm{a}}$ & $\beta$ (s.e.) & $\mathrm{P}$-value $\mathrm{e}^{\mathrm{a}}$ & $\beta$ (s.e.) & $\mathrm{P}$-value $\mathrm{e}^{\mathrm{a}}$ \\
\hline \multicolumn{7}{|l|}{ Retinal arteriolar caliber (CRAE) } \\
\hline Normal BP & $-4.1(0.7)$ & $<0.0001$ & $-4.3(0.7)$ & $<0.0001$ & $-3.6(0.6)$ & $<0.0001$ \\
\hline High normal BP & $-6.5(0.7)$ & $<0.0001$ & $-6.7(0.7)$ & $<0.0001$ & $-5.7(0.6)$ & $<0.0001$ \\
\hline Grade 1 hypertension & $-8.5(0.7)$ & $<0.0001$ & $-8.8(0.7)$ & $<0.0001$ & $-8.1(0.6)$ & $<0.0001$ \\
\hline Isolated systolic hypertension & $-1.8(0.6)$ & 0.003 & $-1.7(0.6)$ & 0.007 & $-1.2(0.5)$ & 0.02 \\
\hline \multicolumn{7}{|l|}{ Retinal venular caliber (CRVE) } \\
\hline Normal BP & $-0.9(1.0)$ & 0.35 & $-1.8(1.0)$ & 0.07 & $1.5(0.9)$ & 0.08 \\
\hline High normal BP & $-1.8(1.1)$ & 0.10 & $-2.9(1.1)$ & 0.008 & $2.3(1.0)$ & 0.02 \\
\hline Grade 1 hypertension & $-1.0(1.0)$ & 0.34 & $-2.1(1.0)$ & 0.04 & $4.8(0.9)$ & $<0.0001$ \\
\hline
\end{tabular}

Abbreviations: BP, blood pressure; DBP, diastolic BP; SBP, systolic BP.

aBP classified according to the European Society of Hypertension and European Society of Cardiology (ESH/ESC) BP categories (optimal, SBP <120 and DBP <80 mm Hg; normal, SBP: $120-139$ and/or DBP: 80-84 mm Hg; high normal, SBP: 130-139 and/or DBP: 85-89 mm Hg; grade 1 hypertension, SBP: 140-159 and/or DBP: 90-99 mm Hg; grade 2 hypertension, SBP: 160-179 and/ or DBP: $100-109 \mathrm{~mm} \mathrm{Hg}$; grade 3 hypertension, SBP $\geqslant 180$ and/or DBP $\geqslant 110 \mathrm{~mm} \mathrm{Hg}$; isolated systolic hypertension, SBP $\geqslant 140$ and DBP $<90 \mathrm{~mm} \mathrm{Hg}$ ).

${ }^{b}$ Model 1: adjusted for age, gender, and ethnicity.

'Model 2: adjusted for age, gender, ethnicity (except for ethnicity-specific models), diabetes status, body mass index, total cholesterol, triglycerides, current drinking and current smoking.

dModel 3: adjusted for variables in Model 2 and also for CRVE (in models of CRAE), and CRAE (in models of CRVE).

e $P$-value, comparing specific group with optimal BP group.

with wider venular caliber had higher incidence of hypertension than those with narrower venules. ${ }^{36}$

Mechanisms underlying the association of BP and retinal arterioles have been previously hypothesized.,38,39 Arteriolar narrowing is thought to result from cumulative arteriolar changes associated with remodeling from chronic hypertension and arteriolosclerosis. ${ }^{3,38}$ Our findings showed that retinal arteriolar narrowing remained evident even in individuals whose BP had been lowered by antihypertensive therapy, suggesting persistent arteriolar damage from chronic hypertension. It has also been suggested that the effect of BP on retinal arterioles is more marked in younger people, as the retinal vessels tend to be more compliant. ${ }^{7,23}$ Conversely, the weaker association of $\mathrm{BP}$ and retinal vessels in older people may reflect age-related increases in rigidity and sclerosis of retinal arterioles, which reduces the impact that BP has on retinal arteriolar diameter compared with younger persons. Our findings support this idea by showing the relationship between MABP and retinal arteriolar narrowing being stronger in younger people than that found in older participants in all three ethnic groups.

In contrast, the pathophysiological mechanisms underlying the effect of BP and venular dilatation remain uncertain. Some studies have shown that wider retinal venules associated with increased BP may be a consequence of chronic retinal hypoperfusion, ${ }^{40}$ cerebral hypoxia $^{41}$ or endothelial dysfunction ${ }^{22}$ from damage to microcircula- 
tion. Another potential mechanism is inflammation, which links hypertension and widening of venules, ${ }^{8,22}$ although consistent relationships have not been found in all studies. ${ }^{42}$

The strength of our study includes a large population-based sample, a variety of potential confounders and standardized methods to measure BP and retinal vascular caliber. This study also includes limitations that should be noted. Its cross-sectional nature limits our ability to assess whether changes in the retinal vascular caliber are antecedent or consequential of elevated BP. Controlling for confounding effect using the contralateral vessel caliber may result in potential over-adjustment of the retinal vascular caliber. ${ }^{34}$ There may also be unmeasured and unknown factors that could have influence on the variation of retinal vascular caliber, such as inflammatory markers for which we could not account. Furthermore, a large number of older participants were excluded from the study and this may result in potential selection bias in our study, for example, older people with narrower arteriolar caliber who were at risk for hypertension were more likely not to participate. Finally, misclassification of hypertension status may have occurred as classification of hypertension was based, in part, on two BP measurements during a single examination. However, such non-differential misclassification would only weaken the associations, suggesting that our observed associations should be even stronger if it was true.

In conclusion, we show the effect of $\mathrm{BP}$ on the retinal vasculature was similar amongst Chinese, Malays and Indians. These findings support the concept that precisely measured retinal vascular caliber from photographs may be a useful tool to study the microvascular changes of hypertension and are relevant in diverse racial/ethnic groups. Assessment of retinal vascular caliber may provide not only insights into early microvascular effects of BP, but may also help guide the development of new antihypertensive treatments.

\section{CONFLICT OF INTEREST}

The authors declare no conflict of interest.

\section{ACKNOWLEDGEMENTS}

The authors thank the staff and participants of the Singapore Prospective Study Program and the Singapore Cardiovascular Cohort Study for their important contributions. This study was financially supported by BMRC Grant 03/1/27/ 18/216, NMRC Grants 0838/2004, IRG07nov013, and STaR/0003/2008, and SBIC Grant C-011/2006

1 Wong TY, Mitchell P. The eye in hypertension. Lancet 2007: 369: 425-435.

2 Wong TY, Mitchell P. Hypertensive retinopathy. N Engl J Med 2004; 351: 2310-2317.

3 Schmieder RE. Hypertensive retinopathy: a window to vascular remodeling in arterial hypertension. Hypertension 2008; 51: 43-44.

4 Wang JJ, Mitchell P, Leung H, Rochtchina E, Wong TY, Klein R. Hypertensive retinal vessel wall signs in a general older population: the Blue Mountains Eye Study. Hypertension 2003; 42: 534-541.

5 Wong TY, Klein R, Klein BE, Meuer SM, Hubbard LD. Retinal vessel diameters and their associations with age and blood pressure. Invest Ophthalmol Vis Sci 2003; 44: 4644-4650.

6 Wong TY, Hubbard LD, Klein R, Marino EK, Kronmal R, Sharrett AR, Siscovick DS, Burke G, Tielsch JM. Retinal microvascular abnormalities and blood pressure in older people: the Cardiovascular Health Study. Br J Ophthalmol 2002; 86: 1007-1013.

7 Wong TY, Klein R, Klein BE, Meuer SM, Hubbard LD. Retinal vessel diameters and their associations with age and blood pressure. Invest Ophthalmol Vis Sci 2003; 44: 4644-4650.

8 Ikram MK, de Jong FJ, Vingerling JR, Witteman JC, Hofman A, Breteler MM, de Jong PT. Are retinal arteriolar or venular diameters associated with markers for cardiovascular disorders? The Rotterdam Study. Invest Ophthalmol Vis Sci 2004; 45: 2129-2134.

9 Leung H, Wang JJ, Rochtchina E, Tan AG, Wong TY, Klein R, Hubbard LD, Mitchell P. Relationships between age, blood pressure, and retinal vessel diameters in an older population. Invest Ophthalmol Vis Sci 2003; 44: 2900-2904.
10 Wong TY, Shankar A, Klein R, Klein BE, Hubbard LD. Prospective cohort study of retinal vessel diameters and risk of hypertension. Br Med J 2004; 329: 79-82.

11 Wong TY, Klein R, Sharrett AR, Duncan BB, Couper DJ, Klein BE, Hubbard LD, Nieto FJ, Atherosclerosis Risk in Communities Study. Retinal arteriolar diameter and risk for hypertension. 2004; 140: 248-255.

12 Smith W, Wang JJ, Wong TY, Rochtchina E, Klein R, Leeder SR, Mitchell P. Retinal arteriolar narrowing is associated with 5-year incident severe hypertension: the Blue Mountains Eye Study. Hypertension 2004; 44: 442-447.

13 Wong TY, Klein R, Couper DJ, Cooper LS, Shahar E, Hubbard LD, Wofford MR, Sharrett AR. Retinal microvascular abnormalities and incident stroke: the Atherosclerosis Risk in Communities Study. Lancet 2001; 358: 1134-1140.

14 Wong TY, Klein R, Nieto FJ, Klein BE, Sharrett AR, Meuer SM, Hubbard LD, Tielsch JM. Retinal microvascular abnormalities and 10-year cardiovascular mortality: a population-based case-control study. Ophthalmology 2003; 110: 933-940.

15 Wang L, Wong TY, Sharrett AR, Klein R, Folsom AR, Jerosch-Herold M. Relationship between retinal arteriolar narrowing and myocardial perfusion: multi-ethnic study of atherosclerosis. Hypertension 2008; 51: 119-126.

16 Levy BI, Ambrosio G, Pries AR, Struijker-Boudier HA. Microcirculation in hypertension: a new target for treatment? Circulation 2001; 104: 735-740.

17 Bild DE, Detrano R, Peterson D, Guerci A, Liu K, Shahar E, Ouyang P, Jackson S, Saad MF. Ethnic differences in coronary calcification: the Multi-Ethnic Study of Atherosclerosis (MESA). Circulation 2005; 111: 1313-1320.

18 Tikellis G, Arnett DK, Skelton TN, Taylor HW, Klein R, Couper DJ, Richey Sharrett A, Yin Wong T. Retinal arteriolar narrowing and left ventricular hypertrophy in African Americans. the Atherosclerosis Risk in Communities (ARIC) study. Am J Hypertens 2008; 21: 352-359.

19 Xue JL, Eggers PW, Agodoa LY, Foley RN, Collins AJ. Longitudinal study of racial and ethnic differences in developing end-stage renal disease among aged medicare beneficiaries. J Am Soc Nephrol 2007; 18: 1299-1306.

20 Conway DS, Lip GY. Ethnicity in relation to atrial fibrillation and stroke (the West Birmingham Stroke Project). Am J Cardiol 2003; 92: 1476-1479.

21 Wong TY, Kamineni A, Klein R, Sharrett AR, Klein BE, Siscovick DS, Cushman M, Duncan BB. Quantitative retinal venular caliber and risk of cardiovascular disease in older persons: the cardiovascular health study. Arch Intern Med 2006; 166: 2388-2394.

22 Wong TY, Islam FM, Klein R, Klein BE, Cotch MF, Castro C, Sharrett AR, Shahar E. Retinal vascular caliber, cardiovascular risk factors, and inflammation: the multi-ethnic study of atherosclerosis (MESA). Invest Ophthalmol Vis Sci 2006; 47 2341-2350

23 Sun C, Liew G, Wang JJ, Mitchell P, Saw SM, Aung T, Tai ES, Wong TY. Retinal vascular caliber, blood pressure, and cardiovascular risk factors in an Asian population: the Singapore Malay Eye Study. Invest Ophthalmol Vis Sci 2008; 49: 1784-1790.

24 Kawasaki R, Wang JJ, Rochtchina E, Taylor B, Wong TY, Tominaga M, Kato T, Daimon M, Oizumi T, Kawata S, Kayama T, Yamashita H, Mitchell P. Cardiovascular risk factors and retinal microvascular signs in an adult Japanese population: the Funagata Study. Ophthalmology 2006; 113: 1378-1384.

25 Hughes K, Yeo PP, Lun KC, Thai AC, Sothy SP, Wang KW, Cheah JS, Phoon WO, Lim P. Cardiovascular diseases in Chinese, Malays, and Indians in Singapore. II. Differences in risk factor levels. J Epidemiol Community Health 1990; 44: 29-35.

26 Tan CE, Emmanuel SC, Tan BY, Jacob E. Prevalence of diabetes and ethnic differences in cardiovascular risk factors. The 1992 Singapore National Health Survey. Diabetes Care 1999; 22: 241-247.

27 Hughes K, Aw TC, Kuperan P, Choo M. Central obesity, insulin resistance, syndrome X, lipoprotein(a), and cardiovascular risk in Indians, Malays, and Chinese in Singapore. J Epidemiol Community Health 1997; 51: 394-399.

28 Cutter J, Tan BY, Chew SK. Levels of cardiovascular disease risk factors in Singapore following a national intervention programme. Bull World Health Organ 2001; 79: 908-915.

29 Wu Y, Tai ES, Heng D, Tan CE, Low LP, Lee J. Risk factors associated with hypertension awareness, treatment, and control in a multi-ethnic Asian population. $J$ Hypertens 2009; 27: 190-197.

30 Jeganathan VS, Kawasaki R, Wang JJ, Aung T, Mitchell P, Saw SM, Wong TY. Retinal vascular caliber and age-related macular degeneration: the Singapore Malay Eye Study. Am J Ophthalmol 2008; 146: 954-959.

31 Wong TY, Knudtson MD, Klein R, Klein BE, Meuer SM, Hubbard LD. Computer-assisted measurement of retinal vessel diameters in the Beaver Dam Eye Study: methodology, correlation between eyes, and effect of refractive errors. Ophthalmology 2004; 111: 1183-1190.

32 Hubbard LD, Brothers RJ, King WN, Clegg LX, Klein R, Cooper LS, Sharrett AR, Davis MD, Cai J. Methods for evaluation of retinal microvascular abnormalities associated with hypertension/sclerosis in the Atherosclerosis Risk in Communities Study. Ophthalmology 1999; 106: 2269-2280.

33 Knudtson MD, Lee KE, Hubbard LD, Wong TY, Klein R, Klein BE. Revised formulas for summarizing retinal vessel diameters. Curr Eye Res 2003; 27: 143-149.

34 Liew G, Sharrett AR, Kronmal R, Klein R, Wong TY, Mitchell P, Kifley A, Wang JJ. Measurement of retinal vascular caliber: issues and alternatives to using the arteriole to venule ratio. Invest Ophthalmol Vis Sci 2007; 48: 52-57.

35 Leung H, Wang JJ, Rochtchina E, Wong TY, Klein R, Mitchell P. Impact of current and past blood pressure on retinal arteriolar diameter in an older population. $J$ Hypertens 2004; 22: 1543-1549. 
36 Liew G, Wong TY, Mitchell P, Wang JJ. Are narrower or wider retinal venules associated with incident hypertension? Hypertension 2006; 48: e10.

37 Ikram MK, Witteman JC, Vingerling JR, Breteler MM, Hofman A, de Jong PT. Retinal vessel diameters and risk of hypertension: the Rotterdam Study. Hypertension 2006; 47: 189-194.

38 Struijker-Boudier HA. Retinal microcirculation and early mechanisms of hypertension. Hypertension 2008; 51: 821-822.

39 Ritt M, Harazny JM, Ott C, Schlaich MP, Schneider MP, Michelson G, Schmieder RE. Analysis of retinal arteriolar structure in never-treated patients with essential hypertension. J Hypertens 2008; 26: 1427-1434.
40 Saldivar E, Cabrales P, Tsai AG, Intaglietta M. Microcirculatory changes during chronic adaptation to hypoxia. Am J Physiol Heart Circ Physiol 2003; 285: H2064-H2071.

41 de Jong FJ, Vernooij MW, Ikram MK, Ikram MA, Hofman A, Krestin GP, van der Lugt A, de Jong PT, Breteler MM. Arteriolar oxygen saturation, cerebral blood flow, and retinal vessel diameters. The Rotterdam Study. Ophthalmology 2008; 115: 887-892.

42 Wong TY, Klein R, Sharrett AR, Manolio TA, Hubbard LD, Marino EK, Kuller L, Burke G, Tracy RP, Polak JF, Gottdiener JS, Siscovick DS. The prevalence and risk factors of retinal microvascular abnormalities in older persons: The Cardiovascular Health Study. Ophthalmology 2003; 110: 658-666. 